\title{
Rock reinforcement solutions case study: Malmberget iron ore mine, Sweden
}

\author{
P. Bray ${ }^{1}$, A. Johnsson ${ }^{2}$, and H. Schunnesson ${ }^{3}$ \\ ${ }^{1}$ Epiroc Rock Drills AB, Sweden \\ ${ }^{2} \mathrm{LKAB}$, Sweden \\ ${ }^{3}$ Luleå University of Technology, Sweden
}

\begin{abstract}
Finding rock reinforcement solutions for poor rock conditions has attracted increased attention in recent years. While modern face drilling, long hole drilling, truck and loader technologies are able to improve productivity, rock reinforcement has become the bottleneck point in the drill and blast process. As a result, the overall productivity of underground hard rock mining has essentially stalled, especially as mines go deeper and deeper in the pursuit of orebodies. Commonly used bolt designs are not necessarily designed for ease of mechanised installation, resulting in long installation times and uncertain installation quality. The industry needs a step change in order to move forward.
\end{abstract}

As part of the ground control work package of the Sustainable and Intelligent Mining Systems (SIMS) initiative, Luossavaara-Kiirunavaara AB (LKAB) and Epiroc Rock Drills $\mathrm{AB}$ partnered in a project to develop a rock bolting system solution to improve the productivity, flexibility, quality and safety of mechanised rock reinforcement.

This paper illustrates the project background, development stages, implementation and results from new technologies that have provided significant improvements in rock bolt and mesh installation at LKAB's Malmberget underground operation.

\section{INTRODUCTION}

Rock reinforcement in many mines has become a significant bottleneck point in the drill and blast cycle. Consequently, rock support productivity has recently attracted much attention Gustafson et al(2016). This is essential for the global mining industry, which despite improved machine capacity for face drilling, long-hole drilling, truck and loader technologies, has faced a significant decreases in productivity since the beginning of the twenty first century Ey and Steen (2018). Where mines go ever deeper in the pursuit of orebodies, the issue of productivity has become even more important.

The global trend in the mining industry towards increasingly mechanized and automated equipment, is also valid for rock support installation equipment; even if differences in mining conditions between regions and countries are significant, Schunnesson and Shekhar (2018). However, since rock support installation is one of the most complicated and difficult operations in a mine, requiring very skilled operators to reach high levels of efficiency, the path to full mechanisation or even automation has proved to be more difficult than anticipated.

What many fail to realise, is that the potential for stoppages during bolt installation for many bolt types, can be very high. Bolt hole blockages, mesh installation, misalignment, cracks, voids and mechanical reliability issues for bolting equipment, singly or in combination, can reduce the level of stoppage free operation. 
As rock support installation is normally done in the vicinity of un-supported rock, the case for the automation of rock support equipment is gathering importance from a safety point of view.

Another important aspect of rock support productivity, is the ability for mechanised rigs to be more flexible in terms of the type of support element that can be installed using a single rig. From a strict productivity point of view, a single rig that can install all support from one setup would be optimal. Manual or semi-mechanized rigs are often much more flexible, although mechanised rock support installation is more specialised, as in the case of bolts and mesh. If cable bolts or straps are required, another installation procedure/rig is required.

This paper describes the results from an initial field test with a newly-developed bolt rig using normal and long self-drilling rock bolts and pumpable bulk resin. This new technique can be a breakthrough step for future rock support technology, with the potential for providing higher productivity, improved quality of installation, greater flexibility and fully-automated rock bolting.

\section{EARLY IDEAS AND DIRECTIONS}

From late 2011, Epiroc has been investigating various technologies with the potential for improving bolt installation productivity. Self-drilling hollow (SDH) bars or self-drilling anchor (SDA) bolts were identified as being able to return significantly positive results in bolting cycle times, especially in poor rock conditions as they would minimize issues related to collapsing bolt holes and not require mesh installation. SDA bolts are characterised by the bolt body acting as a drill steel during drilling and installation with percussive rotation rock drills. The bolt body is hollow; acting as a flushing channel during drilling, and as an injection channel for bonding media during final installation. To drill into rock and broken ground, the bolt has a sacrificial drill bit that remains in the hole after installation. Figure 1 illustrates the main characteristics of a typical SDA bolt installation.

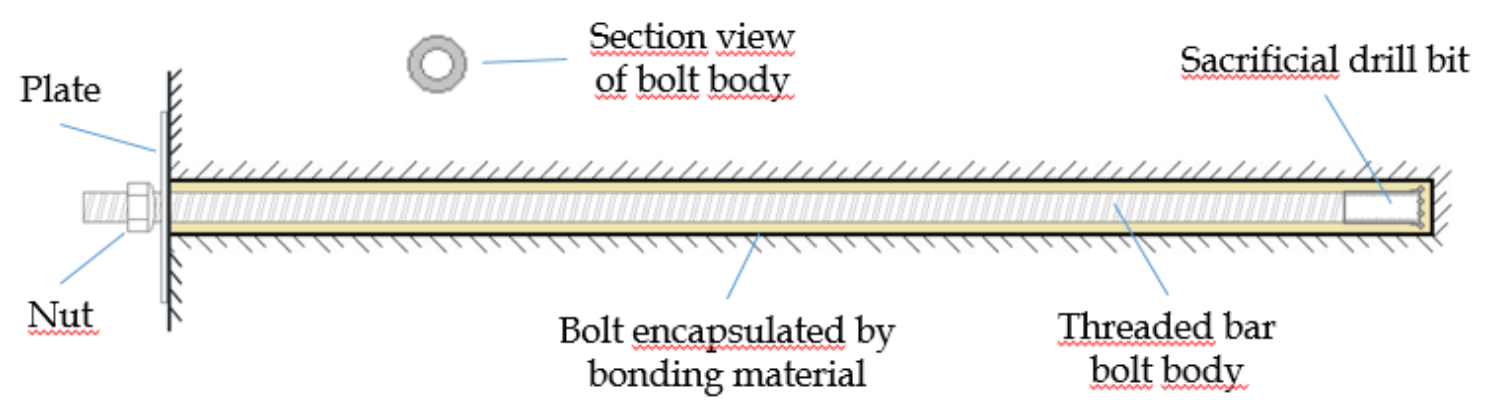

Figure 1. Diagram of a self-drilling anchor bolt installation

SDA bolts are not a new product, and have been used extensively with pumped cementitious grout as the bonding agent in civil applications such as soil nailing, micro piling, slope stabilisation and spiling activities for many years, Irvin et al (2014). Their use in hard-rock underground mining applications had been generally limited to situations where ground conditions did not allow for the installation of other commonly used bolt-types such as resin cartridge rebars or cement-grouted rebars. The unit cost of the SDA bolt was the most common reason why the SDA bolt system has not been widely adopted. In order for a SDA bolting system to be viable, the unit cost of the bolt would need to be offset by superior productivity and quality of installation. To achieve this end, Epiroc concluded that a fastsetting bonding agent rather than slow-setting cementitious grout was required. A pumpable product with similar setting times to the commonly used resin cartridges was needed.

The problem with the material used in resin cartridges, is its relatively high viscosity - which makes its use in a pumpable system unfeasible. A new chemical formulation was required. 
Epiroc approached Sika and Minova to find out if they had any such chemical products available that would fulfil the pumpability and fast setting time requirements. Both companies had products that had been used previously as ground consolidation products. Both products were of a two-component type where once the two components were mixed together, a chemical reaction occurred. This would result in a solid product suitable for transferring loads from the rock mass to the steel bolt. Although the results from the initial test with the pumpable resins were encouraging, the resin characteristics needed adjustments regarding setting time and thickening of the mixed resin to prevent resin leaking from the bolt hole. Figure 2 shows an early test of pumpable resin at Epiroc's Nacka test mine, Sweden.

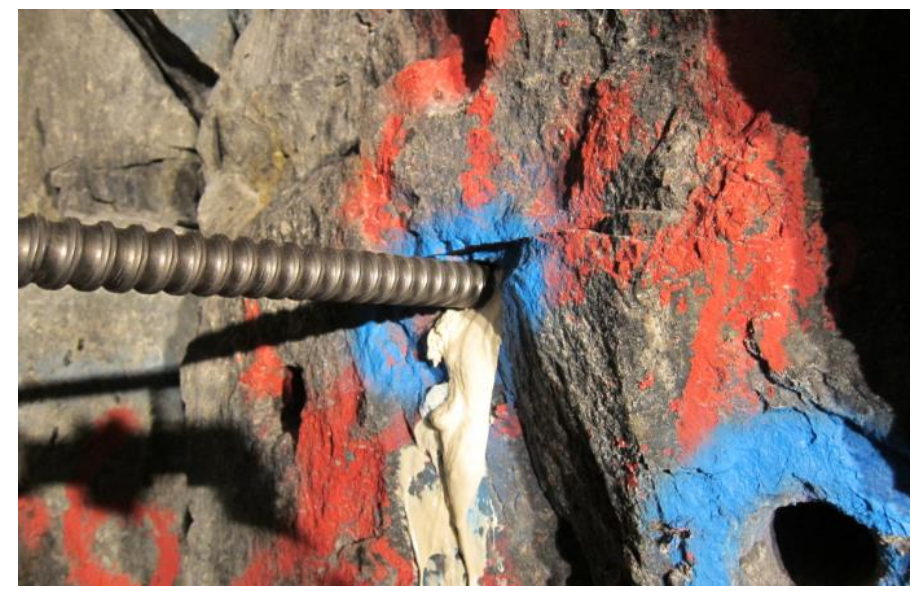

Figure 2. Early testing of pumpable resin showing "runny" nature of the resin

The period from 2012 to mid-2015 was characterised by many brainstorming sessions and investigations of potential solutions. During this time, LKAB indicated they wanted to participate in the development work for solutions to increase rock bolting productivity. LKAB were encountering increasing difficulties with rock bolt installation and were ideally positioned to evaluate potential solutions resulting from their project work. As a base line comparison, LKAB evaluated the productivity statistics for their existing bolting systems productivity numbers. There were many technical challenges during this period, with several ideas with high potential ending in a dead end with no way out. In mid-2015, the adaptation of the Sustainable Intelligent Mining Systems (SIMS) initiative, coupled with some new technical solutions, allowed the project to focus and gain significant pace. Internally, the project was dubbed the High Performance Boltec (HP Boltec) project.

\section{SUSTAINABLE INTELLIGENT MINING SYSTEMS (SIMS)}

The Sustainable Intelligent Mining Systems project (SIMS) (https://www.simsmining.eu/) is a Horizon 2020 project sponsored by the European Union. The goals of the SIMS initiative were to provide funding and a framework for mining companies, equipment and systems suppliers and leading universities to collaborate on various work packages that address various aspects of the mining industry. The project's aims were to realize the vision of a sustainable intelligent mine with safe working conditions, high efficiency and low environmental impact. To achieve these goals, several new, innovative and disruptive technologies, processes and methods must be implemented in the mining industry today and in the future. These new technologies are being tested and demonstrated within the SIMS project. The SIMS partner organisations are shown in Figure 3. 


\section{eEpiroc}

\section{AGNICO EAGLE

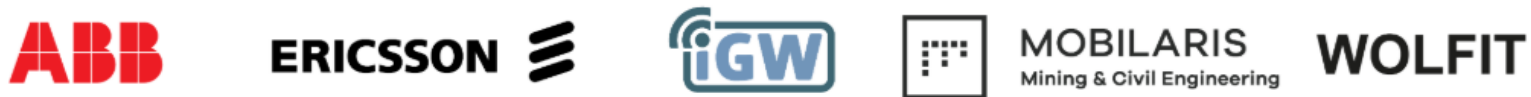

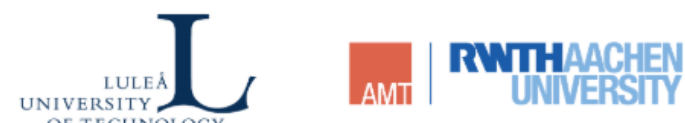

Figure 3. Organisations involved in the Sustainable Intelligent Mining Systems project

\section{SIMS GROUND CONTROL WORK PACKAGE}

The ground control work package within the SIMS project was originally coordinated by Luleå University of Technology, with organizational control later being moved to LKAB. The work package aims to use state-of-the-art ground support methodology, techniques, and monitoring technology, and applying them in real mining environments. It is using the knowledge gained to enable fast and safe ground control throughout the demonstration mines to improve control of seismic vibrations and seismic damage.

The work package tasks include the following:

1. Optimisation of production blasting parameters conducted for a group of faces, aiming for elasticwave effect amplification.

2. Improvements in rock bolt and mesh installation efficiency.

3. Extraction of face material detection.

4. Roof crack detection.

5. Field trials, evaluation and exploitation.

The case study on which this paper focuses, concerns the second task: Improvements in rock bolt and mesh installation efficiency.

\section{Project history, milestones and scope}

Work relating to support-installation efficiency improvements, commenced in August 2015. The LKAB Malmberget field trial was the culmination of this work and was completed in October 2018. The major milestones of the project are shown in Figure 4.

Optimizing design + test subsystem Final assembly prototype + start up Internal tests and modifications Jan $16^{\prime}-$ May $17^{\prime}$ May $17^{\prime}$ - June 17' Nov $17^{\prime}$ - Feb 18'

$\begin{array}{ccc}\text { Material sourcing } & \text { Rebuild rig with resin system + start up } & \text { Field test + rebuild, delivery LKAB } \\ \text { Jan 17' - May 17' } & \text { Aug 17' - Oct 17' } & \text { Feb 17' - Oct 17' }\end{array}$


As several of the technologies under development were new and untried, the original scope of the project, as of August 2015, prioritised the following tasks:

1. Build and test in- house a proof of concept (POC) Boltec machine, with self-drilling anchors (SDA) and bulk resin.

2. Design mixer and adaptor.

3. Develop mixer magazine.

After some significant technological advances were achieved, the project scope was further refined in September 2016 to include the following chief tasks:

1. Build a fully-functional POC rig that will be used in production with a minimum of 7.7 bolts per hour working productivity.

2. Make both SDA installation and two-step hollow bolt installation available on the POC rig.

3. No resin leakage during injection.

4. Field test at LKAB Malmberget, 2000 bolts or 4 months.

5. POC rig documentation (spare parts, operator and safety manual, operator education) for field test.

6. Design a resin distribution and refilling system above ground and underground.

7. Supply an appropriate selection of spare parts and volumes needed for the field test.

8. Provide service instructions for the resin system.

9. Rebuild rig to standard $\mathrm{LKAB}$, Boltec EC requirements after field test (if required).

Responsible organisations involved in the work were:

1. Luleå Technical University (LTU) - Initial Work Package Administration \& Results Analysis.

2. LKAB - Field test location, equipment operation and industry reference, later work package administration.

3. Epiroc Rock Drills $\mathrm{AB}$ - Bolting equipment development including integrated resin pumping system, mechanised bolt installation \& injection system.

\section{FIELD TEST DESCRIPTION}

\section{Site description}

The field test was conducted in the Malmberget underground iron ore mine and operated by LKAB, owned by the Swedish government. The Malmberget mine is the second-largest underground iron ore mine in the world and is located in northern Sweden, $100 \mathrm{~km}$ north of the Arctic Circle, close to the municipality of Gällivare. Large-scale mining activities in the Malmberget area have taken place since 1888 , and all mining operations shifted underground during the 1920s. The mine is divided into two major ore fields; the eastern and western fields, and consists of about 20 large and small ore bodies distributed over an area of approximately $2.5 \times 5 \mathrm{~km}$ (north-south/east-west).

Production is currently being carried out in about half of the ore bodies, Shekhar et al (2017). The orebodies are mainly composed of magnetite with hematite intrusions in some areas, mostly in the western field. The current production areas are normally between the previous haulage level at $1000 \mathrm{~m}$ and the new one at $1250 \mathrm{~m}$. The mining method in use at Malmberget is sub-level caving (SLC), considered to be appropriate method for larger scale underground mining. Production during 2017 was 13 million tonnes of ore, which translated to 9 million tonnes of saleable product.

The rock conditions in Malmberget vary between the different areas, but increasing seismic activity with deeper mining has placed additional demands on the required rock support. Increasing quantities of ore are also being mined from within areas known to be susceptible to seismicity, and from within areas affected by highly-challenging geological conditions. Over 170 geophones are located throughout the underground workings to monitor seismicity and identify hazardous areas, and a great deal of emphasis is placed on installing proper support underground. Figure 5. illustrates one of the areas within the mine where ground conditions were particularly difficult, with heavy rock reinforcement in evidence. 


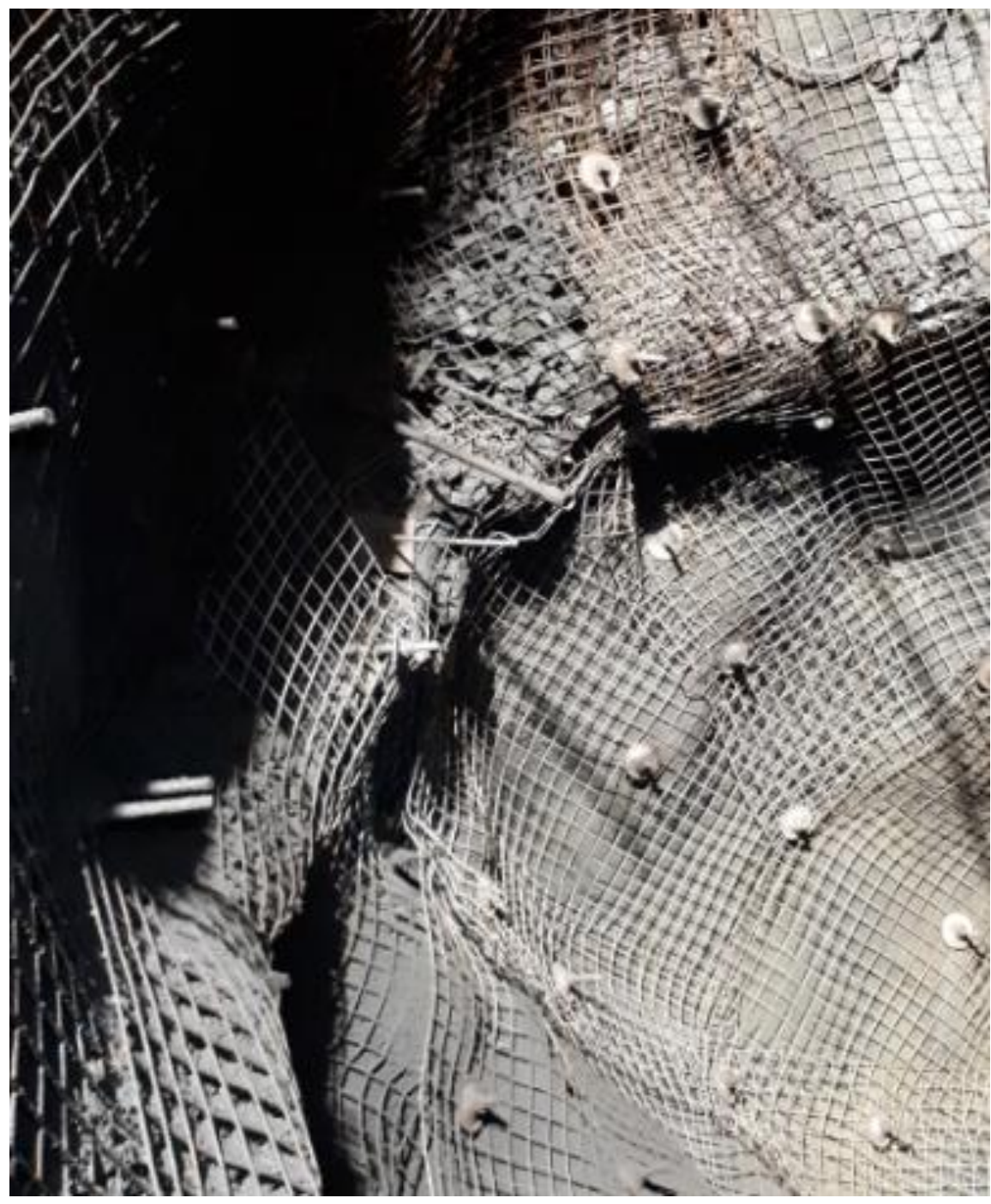

Figure 5. LKAB Malmberget mine, example of area of difficult ground conditions

The rock support installations in Malmberget mine are fully mechanized, with the mine using nine bolting rigs owned and operated by LKAB and a further six rigs owned and operated by contractors. For rock support, the mine uses cement grouted rebar (static) and D-bolts (yielding - see Figure 6), cement-grouted cable bolts, mesh/screen support and shotcrete/steel-fibre reinforced shotcrete. The mine has a detailed plan (standard operating procedure) for all rock support. Figure 7 . shows the standard $1 \mathrm{~m} \times 1 \mathrm{~m}$ bolting pattern for Dynamic (yielding) $3 \mathrm{~m}$ D-bolt installation, including $100 \mathrm{~mm}$ steel fibre reinforced shotcrete and welded steel mesh.

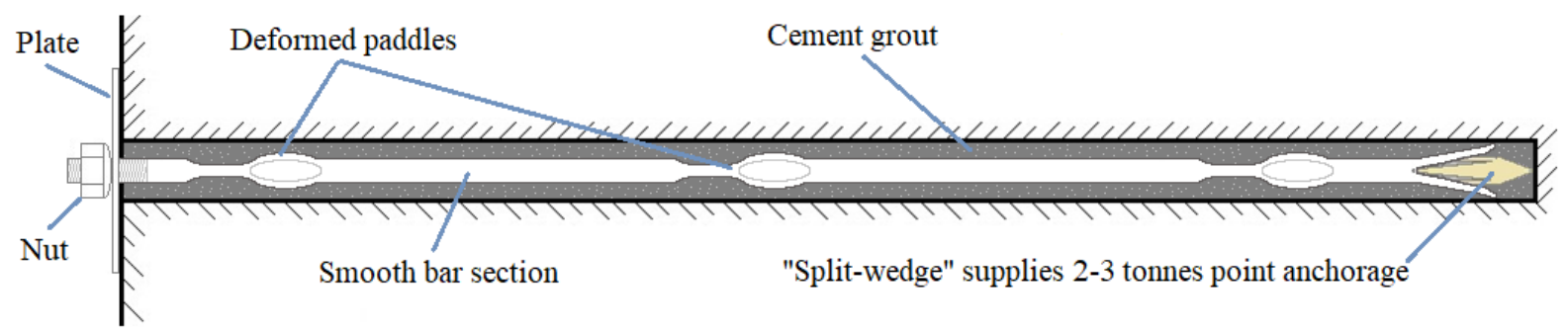

Figure 6. Diagram of yielding D-bolt installation 


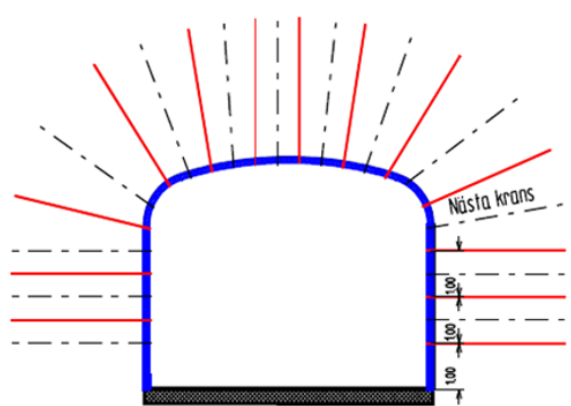

100MM FIBREARMERAD SPRUTBETONG

GÄLLER SULA-SULA

NÄTARMERING

MINST 3 RUTORS ÖVERLAPPNING

NÄTARMERING SLUTTAR 1M ÖVER FÄRDIG VÄGBANA

BULT

C/C BULT = 1M I TVÄR-OCH LÄNGSLED

VÄGBULT SLUTAR 1M ÖVER FÄRDIG VÄGBANA

OBS!

ANTAL BULT VARIERAR BEROENDE PÅ ORTPROFIL

BULTTYP

DYNAMISK BULT

\section{FÖRKLARINGAR}

SYSTEMBULTNING ENLIGT FIGUR

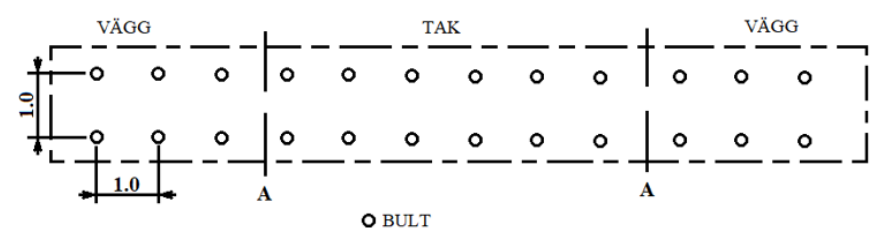

SKARVNING AV NÄT

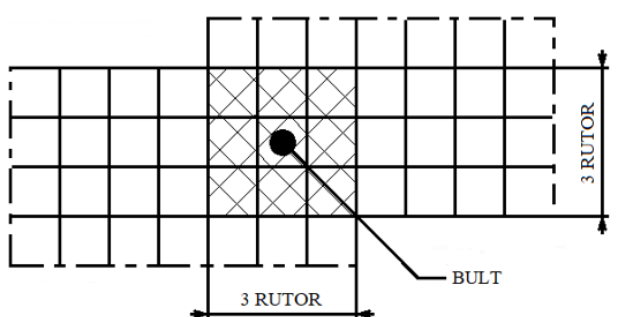

Figure 7. Systematic dynamic bolt installation design

\section{Rig description}

The bolting rig used for the field test at LKAB's Malmberget mine was a Boltec EC manufactured by Epiroc Rock Drills AB, Sweden. The Boltec EC can be described as a fully mechanised rock bolting drilling machine designed for rock bolt installation in underground mining and tunnelling applications. A diesel engine powers the machine which uses a high voltage $(1000 \mathrm{~V} / 50 \mathrm{~Hz})$ electrical system driving hydraulic pumps which provide hydraulic power for a rock drill, boom and feed positioning systems and other hydraulic functions. Epiroc has manufactured underground mining and tunnelling equipment for many years, and is among the market leaders in the development of such equipment.

Figure 8 illustrates the Boltec EC and the locations of the key components of the machine used during the LKAB Malmberget field trial.

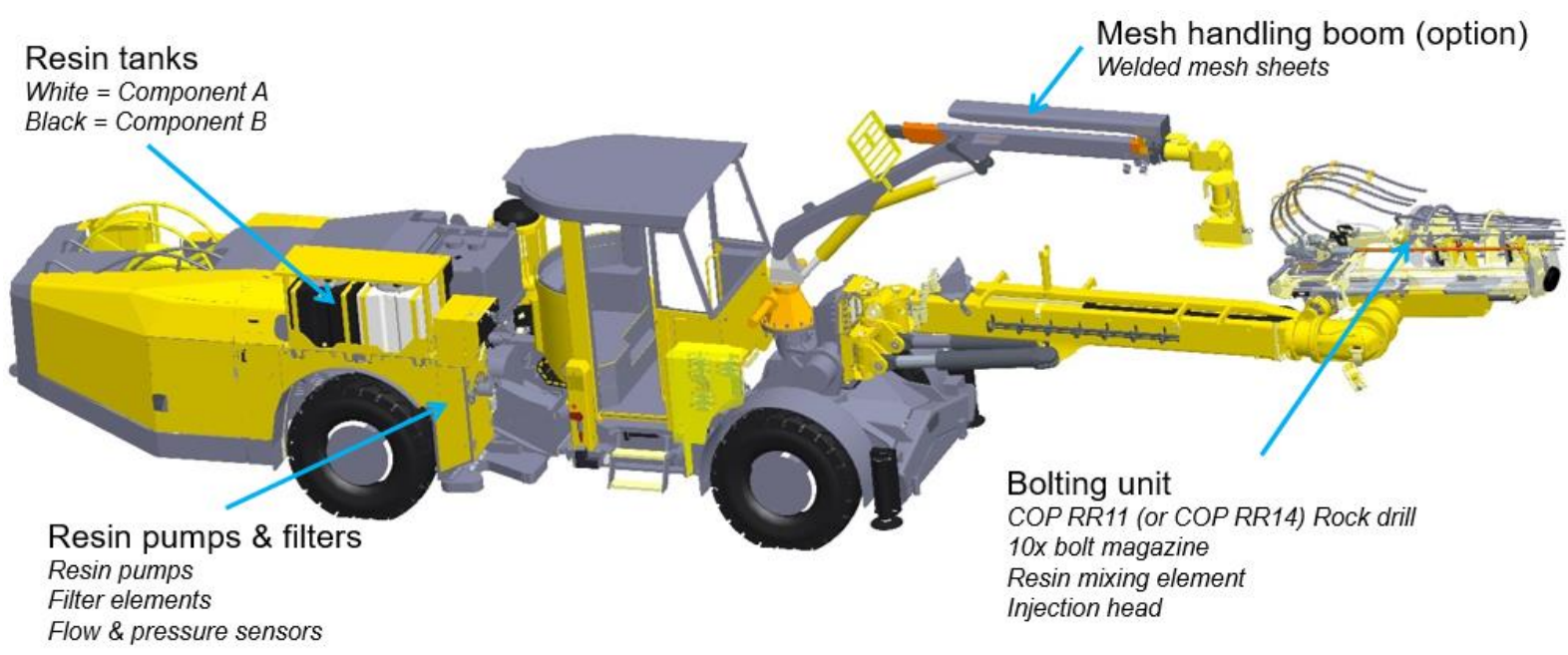

Figure 8. Field test Boltec EC with key components indicated 
The new items that were developed specifically for the field test machine included:

1. On-board resin tanks (200 litres each of component A and component B - 170 litres of each useable).

2. Pumping system with minimal pressure \& flow fluctuations.

3. Pumping monitoring system to ensure mix ratios are maintained.

4. Refilling system for on-board tanks which allowed filling while still installing bolts.

5. Integrated software control of the pumping and injection system with safety cut-outs if pumping pressure or pumping flows exceeds defined parameters.

6. New shank developed to work with SDA-type bolts.

7. New drill steel support with three positions (full open, guide and grip).

8. Resin mixing system that allowed multiple injections without need for replacement.

9. Mixing system flushing design, which creates a closed system with minimum maintenance requirements.

\section{Self-drilling bolts}

The bolts used in the field test were self-drilling with a welded bit and a central hole, through which resin is pumped (See Figure 9). The self-drilling technique is optimal in broken rock and in rock with a lot of water since the bolt is installed during the drilling process and does not have to be inserted after drilling the hole.

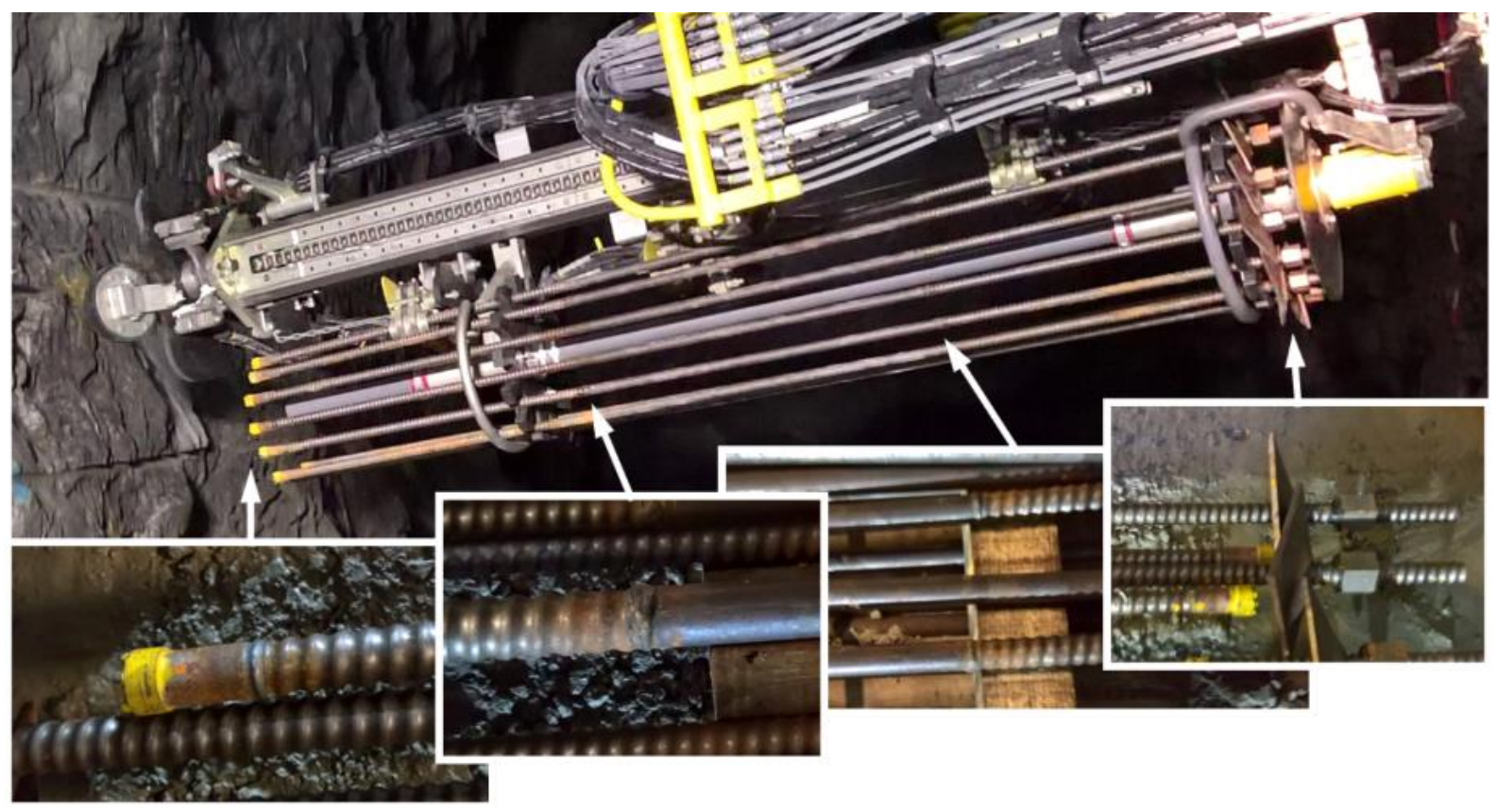

Figure 9. The self-drilling bolts used

The specific bolts used are $3.05 \mathrm{~m}$ long CB R28/200 bolts, manufactured by Minova (part of the Orica group). The drilled length is approximately 2.8 to $3.0 \mathrm{~m}$. The bolts have an ultimate load of $210 \mathrm{kN}$, a yielding load of $145 \mathrm{kN}$ and an elongation yielding section of $200 \mathrm{~mm}$.

The bolt consists of a bit, a threaded section, a yielding section and another threaded section containing the plate and the nut. The bolts are welded at three different locations - the first between the bit and bolt body, and the second and third between the threaded and smooth dynamic section of the bolt body, as shown in Figure 10. 


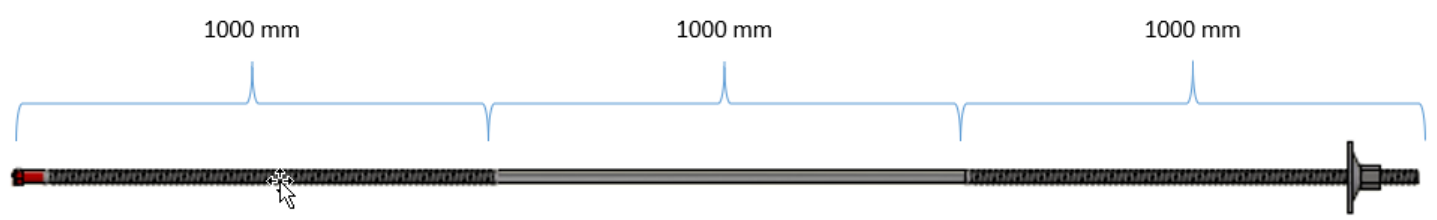

Figure 10. Diagram of yielding SDA bolt used during Malmberget field test

\section{Resin}

The resin used during the field trial was supplied by Minova, part of the Orica group. The resin is a polyurea silicate resin (CARBOTHIX 150710) that consists of component A and component $\mathrm{B}$. The density of component $A$ is $1430 \mathrm{~kg} / \mathrm{m}^{3}$ and component $B$ is $1160 \mathrm{~kg} / \mathrm{m}^{3}$. Figure 11 shows the intermediate bulk containers (IBC) that were used to refill the on-board tanks located on the machine.
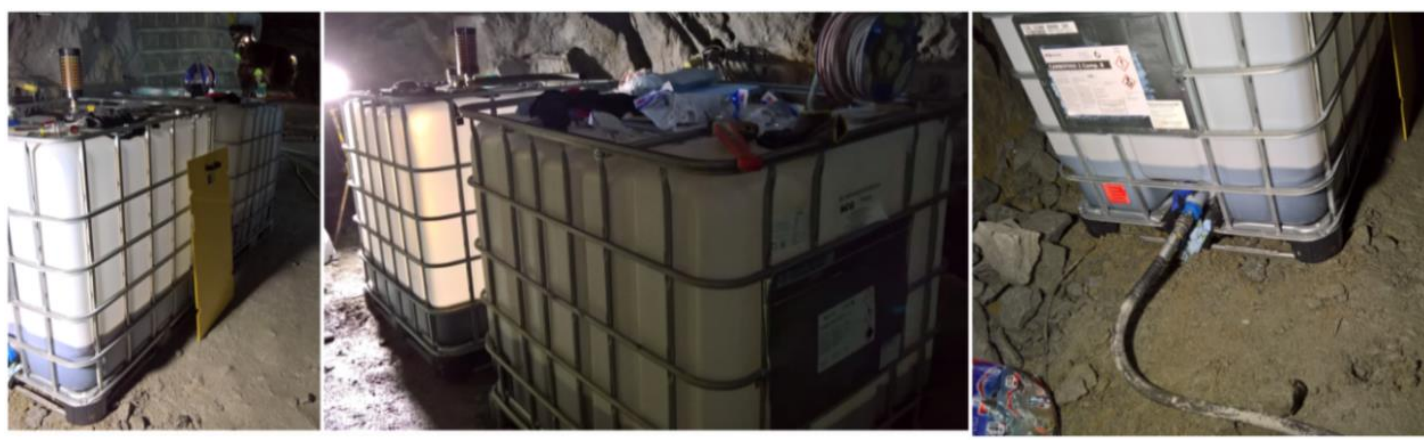

Figure 11. IBC containers $\left(1 \mathrm{~m}^{3}\right.$ each) for component $A$ and component $B$ that are used to refill the on-board tanks

Minova adjusted the resin properties to deliver a chemical compound which provided a setting time of $15-30$ seconds in an operational temperature range of $10-15^{\circ} \mathrm{C}$. During the field test, the average underground temperature at Malmberget was closer to $17^{\circ} \mathrm{C}$, which meant that the setting time was closer to 10-12 seconds. This shorter setting time was still acceptable and worked well during the field test.

The pumping system on the Boltec EC was designed with the option for the machine to either pump directly from off-board IBC containers or from on-board tanks. Figure 12 shows the on-board tank installation on the machine. In practice, this means that a slower setting speed resin can be used in areas where extension drilling operations are required. Owing to the increased resin volumes typically used for extension drilling holes, a slower setting time is indicated. 


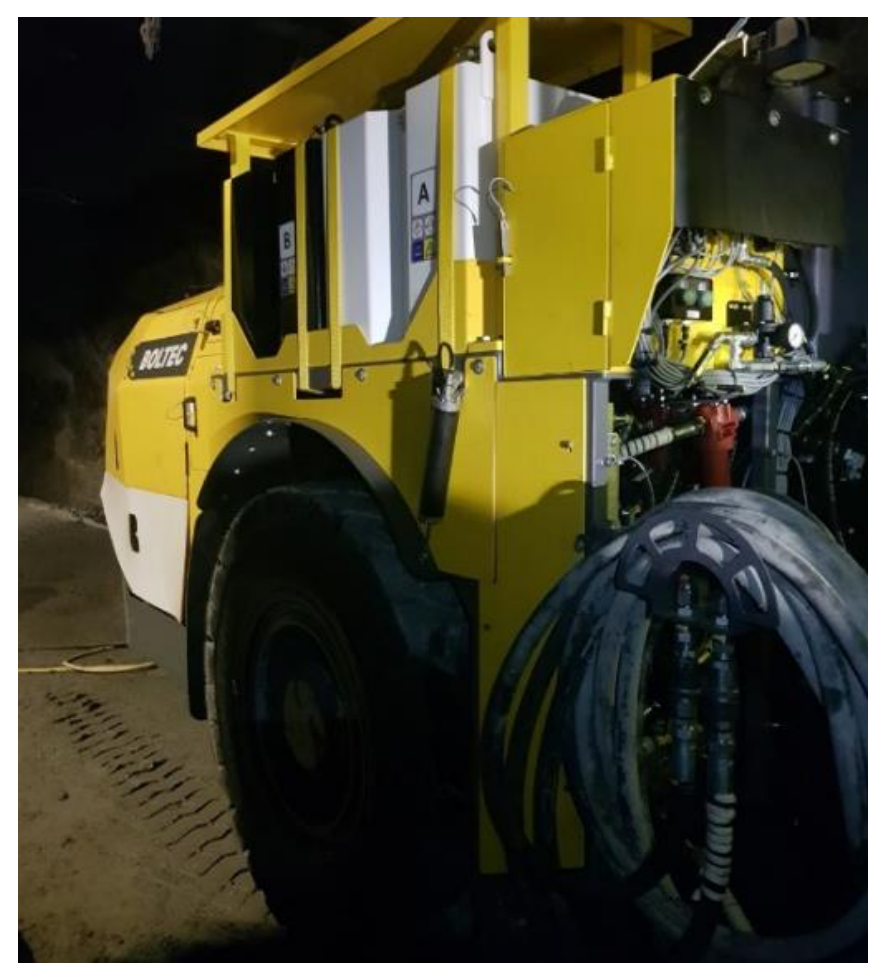

Figure 12. The containers for component $A$ and component $B$ on board the rig

The estimated consumption of resin is 1.4 litres for a $3 \mathrm{~m}$ bolt ( 0.7 litres of component A and 0.7 litres of component B). This can, however, increase substantially in fracture zones or cavities. Up to 240 bolts can be installed per on-board container, when filling under ideal conditions.

The average resin consumption measured during the field trial was 1.8 litres -2.0 litres per hole. This indicates that the rock conditions encountered during the field test did indeed contain some cracks and voids.

\section{RESULTS}

\section{Normal bolting}

The field test started in April 2018 with a two-day pre-training course for specific LKAB personnel regarding the correct handling procedures for the resin to be used in the trial. Delivery and commissioning of the machine was carried out between 2 May and 6 June 2018. During this period, owing to issues associated with the resin mixer flushing system, only 129 bolts were installed during this period. Once the issues were resolved, some 1155 bolts were installed during the main field test period from 7 June to 29 August.

Note There was a vacation period between 18 July and 14 August, with the machine standing idle during this time.

The test in Malmberget was conducted measuring the work capacity, Gustafson et al (2016), i.e., the productivity of the machine while in position at the working face. In Figure 13, the face time and the total installed bolts are presented together with the calculated work capacity in bolts per hour. During the field test, the machine was only in operation during the 8-hour day shift. The test period was too short to accurately define logistic delay time, maintenance time and utilisation, which always significantly decrease the long-term capacity of a bolt rig. However, the high maintenance time and cleaning time associated with cement grouting, can be assumed to be significantly reduced with this 
new rig. Operators of the machine commented on how much easier it was to operate the pumpable resin system in comparison with their usual cement grouting machines.

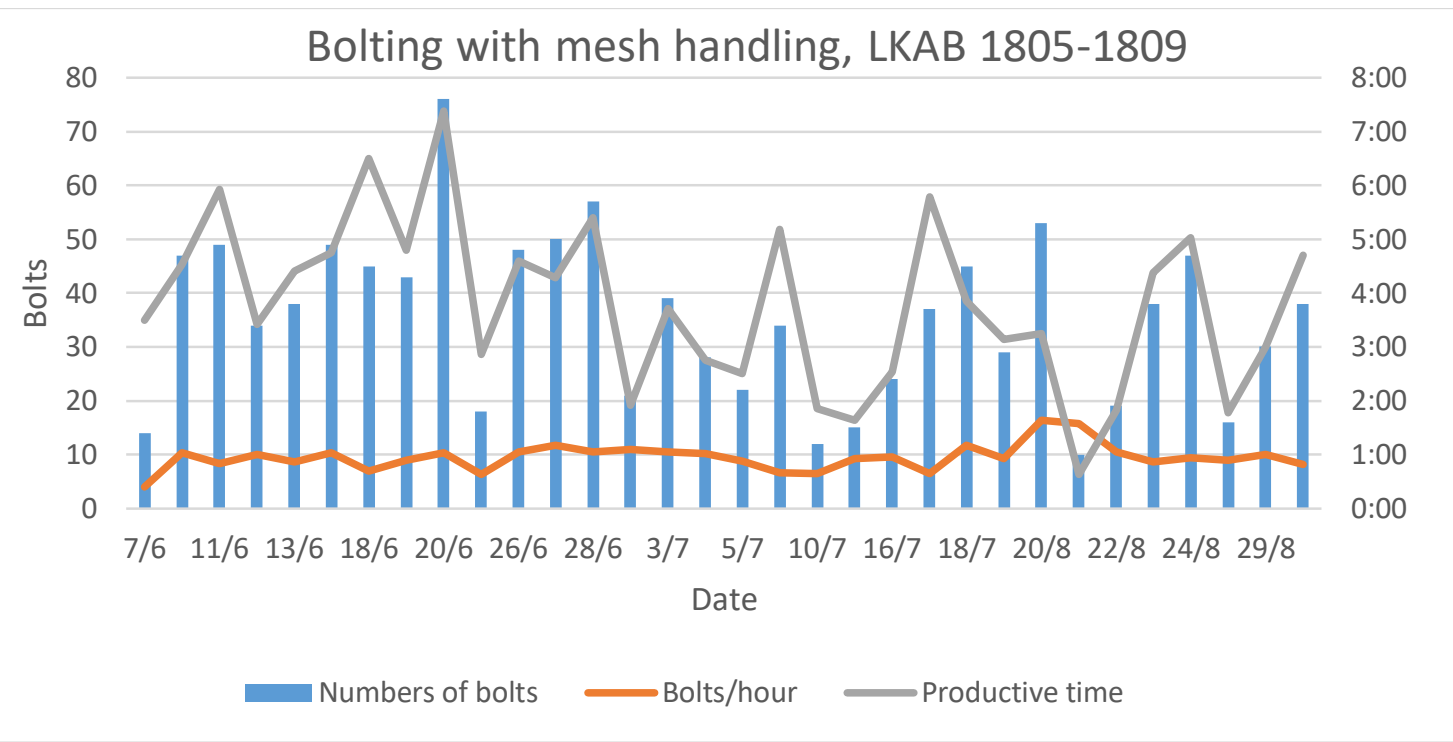

Figure 13. Productivity results achieved during the Malmberget field test

Despite the short field test period, the average bolts per hour worked achieved by the SDA and pumpable resin with mesh installation, was 11 bolts per hour. This represented a $64 \%$ improvement in productivity when compared to the existing cement-grouted D-bolt installation with mesh. The result was considered most satisfactory, considering that the machine was a prototype with small improvements being implemented during the test.

Additionally, operators were still learning how best to operate the machine during the test period. When asked, the operators of the machine both agreed that they could achieve even better results given additional time on the machine.

Compared to earlier studies, Gustafson et al(2016), the achieved productivity compares well compared to the use of cartridge resin, and is significantly higher than achieved in earlier studies for bolt rigs using cement-grouted bolts. The drilling time using specialised bits and rods for the self-drilling bolts is slightly higher than for normal bolt drilling. Th additional time is however compensated for by the time saved by eliminating the need for drill rod removal / bolt insertion required in traditional bolting operations. In fractured and broken rock however, installation times for cartridge resin and cementgrouted bolts typically will increase due to difficulties experienced inserting the cartridges or grout injection hose into the bolt holes.

To check on the quality of the SDA bolt installation, an external company performed pull tests on 55 bolts in various locations. The bolts were pulled to 20 tonnes (not to failure) with all tested bolts exceeding the 20-tonne threshold requirement.

\section{Long hole bolting}

One of the standard support designs used in Malmberget for poor rock conditions, is shown in Figure 14. The support is a combination of normal bolts, mesh/screens and cable bolts. Currently the installation work requires two different rigs, the first for bolts and mesh/screens installation and the second for the installation of cable bolts. The installation of cables can be complicated, particularly in badly fractured or broken rock, and the installation of cables into the drilled hole, can be very time consuming. During the field test, there was an opportunity to try to drill longer holes with self-drilling bolts using extension rods. 


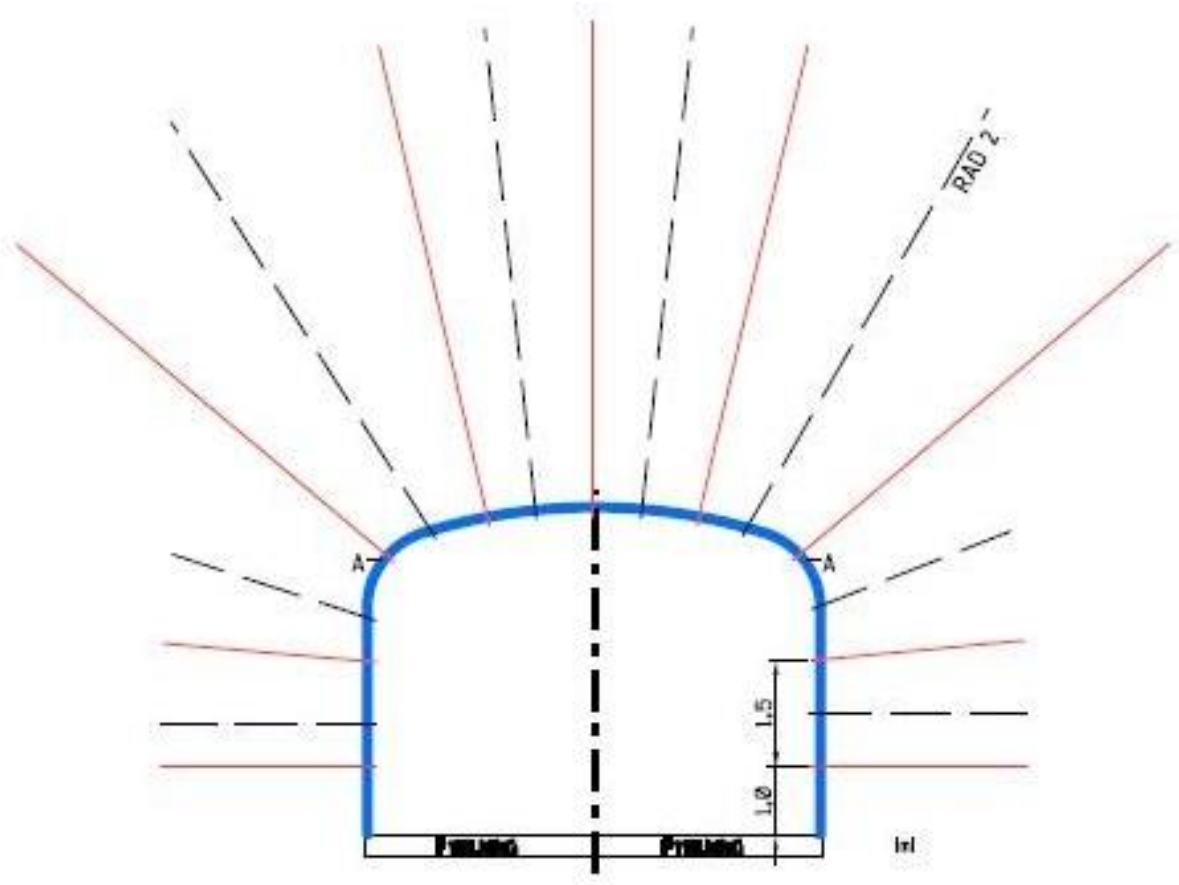

Figure 14. Combination cable bolt and rock bolt design

Although a limited number of holes were drilled, the test was successful. Holes up to a length of $15 \mathrm{~m}$ were drilled with successful introduction of resin. Some modification to the composition of the resin was made to increase the hardening time. Figure 15 illustrates the extension drilling configuration for the SDA bolts in the bolt magazine. Note that the extension couplings are located on the top side of the extension rods owing to the use of the female shank adaptor on the rock drill.

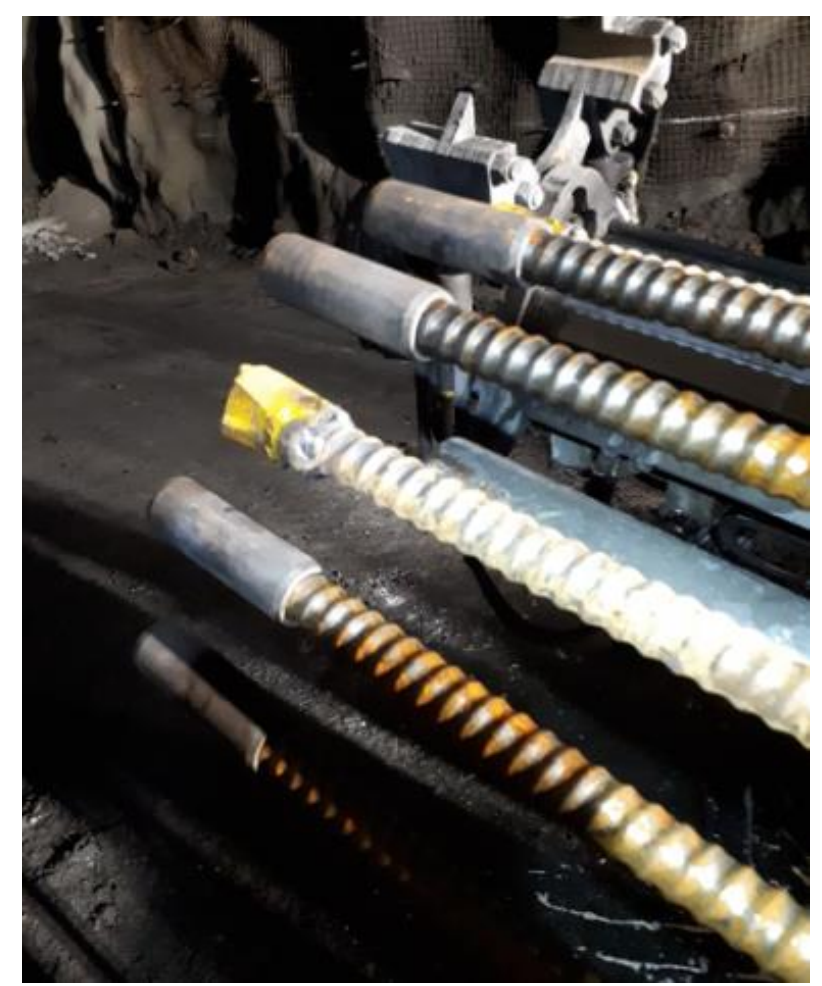


Figure 15. Extension drilling setup in the bolt magazine for $9 \mathrm{~m}$ bolts ( $3 \times 3 \mathrm{~m}$ sections)

Fully mechanising the extension drilling and resin injection process greatly improves operator safety and productivity in poor ground conditions. The possibility of installing all support by using one rig only is very attractive from a productivity point of view. The positive results of this test open up new possibilities for improving both productivity and quality of support installation.

\section{CONCLUSION}

The following conclusions can be drawn from the field test:

- The bolt installation time for tested pumpable resin system, compares well with earlier tests for cartridge resin and is significantly shorter than cement-grouted bolt installation time.

- Compared to cartridge resin, this new system has the potential to reduce the time spent transporting resin boxes to the machine as well as reducing the operator's time spent outside the protected rig cabin handling resin cartridges. This is an important step towards full automation where all manual intervention is reduced.

- In fractured and broken rock, the benefits of the system increases, since the SDA bolt remains in the hole, eliminating issues with bolt hole blockages.

- The successful test with installation of up to $15 \mathrm{~m}$ self-drilling bolts indicates the potential to replace traditional cement grouted cable bolts in areas where ground conditions inhibit effective cable bolt installation. This could be especially applicable for such tasks as rehabilitation/repair of damaged excavations - where the ability to have a single machine capable of installing mesh / screens, single length bolts and extension drilling bolts could be an attractive option.

\section{REFERENCES}

Ey, P. M. and Steen, P. Productivity in mines: a case for broad transformation. https://www.ey.com/Publication/vwLUAssets/EY-Productivity-in-mining/\%24File/EYProductivity-in-mining.pdf, [Accessed 9 January 2019].

Gustafson, A., Schunnesson, H., Timusk, M. and Hauta, R. (2016). Productivity of rock reinforcement: methodology development. Journal of the Southern African Institute of Mining and Metallurgy, December, 2016.

Schunnesson, H. and Shekhar, G. (2018). International survey on mining practices in Surface Support. MIGS report, WP-22, December 2018.

Shekhar, G., Gustafson, A. and Schunnesson, H. (2017) Loading procedure and Draw Control in LKAB's Sublevel Caving Mines: A Baseline Mapping Report. Research report, ISBN 978-91-7583-807-6 (electronic). Luleå University of Technology, Sweden, 60pp.

Irvin, C (2014) Self-Drilling Hollow Bars: Ground Anchor, Tension Pile or Soil Nail, Deep Foundations Institute - International Society for Micropiles 2014 


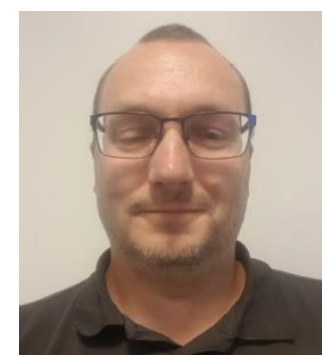

\section{Peter Bray}

Global Product Manager - Rock Reinforcement Equipment

Epiroc Rock Drills AB

From 2000 to 2005 had worked for Epiroc in Australia as Product Manager - Tunnelling and Mining Equipment in support for the Australian Customer Centre. During September 2005 had the opportunity to move to Epiroc's main underground equipment factory in Örebro, Sweden with the role of Regional Business Manager - Service. In 2008 changed role to Global Product Manager - Face Drilling equipment, then in 2013 changed roll again to Global Product Manager - Rock Reinforcement Equipment. The existing role has responsibility for Epiroc's range of bolting and cable bolting equipment, acting as the link between marketing and technical responsibilities. A strong focus is maintained with ensuring that the equipment under development will meet industry demands now and in the future.

\section{Anders Johnsson}

Project Leader

LKAB

Began working for LKAB in 1986 at Malmberget underground iron ore operations. Gained extensive experience in operational aspects of mining until 1998. In 1998 joined the Research and Development department of LKAB's Mining Technology group as a technician helping to evaluate and develop new mining technologies. In 2013 started as a project leader for the same group. Over the years have been project leader for projects involving the LOADRITE weighing system, Wireless online loading information system (WOLIS), Caterpillar's remote loading system, Sandvik's remote loading system \& most recently Epiroc's High Performance Bolting \& Mesh installation system.

\section{Håkan Schunnesson}

\section{Professor \\ Luleå University of Technology}

Håkan Schunnesson is professor at Luleå University of Technology, Sweden, holding a LKAB Chair in Mine Production at the Division of Mining and Geotechnical Engineering. He has over 90 international publications in International Journals and in Peer-reviewed international conferences. He has been editor for proceedings from high quality symposium such as MassMin, Fragblast, MPES etc.

Håkan Schunnesson has been examiner for 18 university courses, both at LTU and in other universities and has been program director for 2 MSc programs in mining and geotechnical engineering. He is presently supervising $8 \mathrm{PhD}$ students, and he has also been examiner and reviewer for a number of $\mathrm{PhD}$ theses both in Sweden and internationally.

Håkan Schunnesson main research interest is in mining equipment, automation and in digital mining. He has lead, and leads, several development projects for practical applications of big data. Over the last 10 years he has successfully been granted 20 research project with a total research funds of $4 \mathrm{M€}$. 
